ing the solution at a lukewarm temperature. In the majority of cases the water which the patient receives is cool or entirely too hot.

The apparatus shown in Figure 2 is arranged for hot saline solution, and in Figure 3 , a warm solution should be used in the upper funnel.

4900 Berlin Avenue.

\section{AN APPARATUS TO KEEP ENTEROCLYSIS SOLUTIONS HOT}

\section{B. B. WECHSLER, M.D.}

Obstetrician to Montefiore Hospital PitTsBuir, PA.

This illustration shows an apparatus devised to keep at a proper temperature the solution for enteroclysis given by the Murphy drop method. This is difficult to accomplish by the usual method.

The apparatus consists of a glass irrigator encaser in a jacket or nest made of copper for the outer wall and tin for the inner wall, having a space of half an inch between the outer and inner walls. An opening at the top fitted with an air-tight lid permits the filling

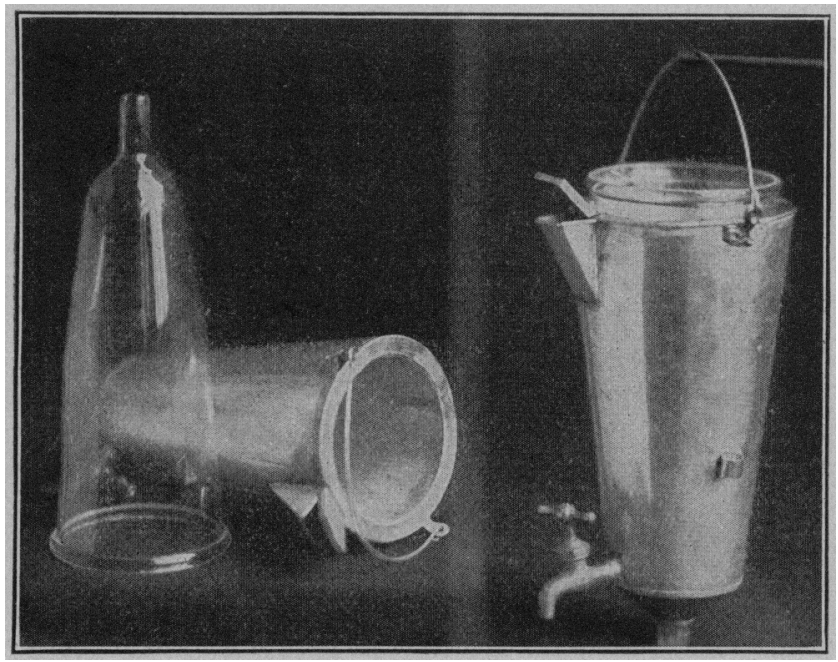

On the left, the glass irrigator and the jacket; on the right. the apparatus ready to use.

of the jacket with hot water, and a stop-cock at the base permits its removal when cold. The jacket is supplied with a handle for its support.

The irrigator protrudes about an inch at the base of the jacket, where the connection can be made. The apparatus is covered with a sterile towel when ready to be used.

Tests at the Montefiore Hospital of Pittsburg, Pa., showed the apparatus to work satisfactorily in every respect. The solution is put into the irrigator at a temperature of $130 \mathrm{~F}$. and hot water used as the heating medium. After three and one-half hours the solution is still at about $110 \mathrm{~F}$.

1401 Fifth Avenve.

Chorea Minor.--Forssner leans to the generally accepted opinion that the symptom-complex of chorea minor may be caused by various infections and possibly also other noxious influences. The results of his observations speak in favor of the tendency of the disease to attack especially individuals of feeble constitution. Many of those who in childhood suffered from chorea minor later acquire numerous chronic diseases.Hygica Festband.

\section{DISLOCATION OF THE KNEE AND DISLOCA-} TION OF THE FOOT

WALTER D. WISE, M.D. BALTIMORE

A case of anterior dislocation of the knee and a case of backward subastragaloid dislocation of the foot with fracture of the astragalus were both seen at the Baltimore City IIospital in the service of Dr. A. C. Harrison, and are reported because of the rarity of the conditions.

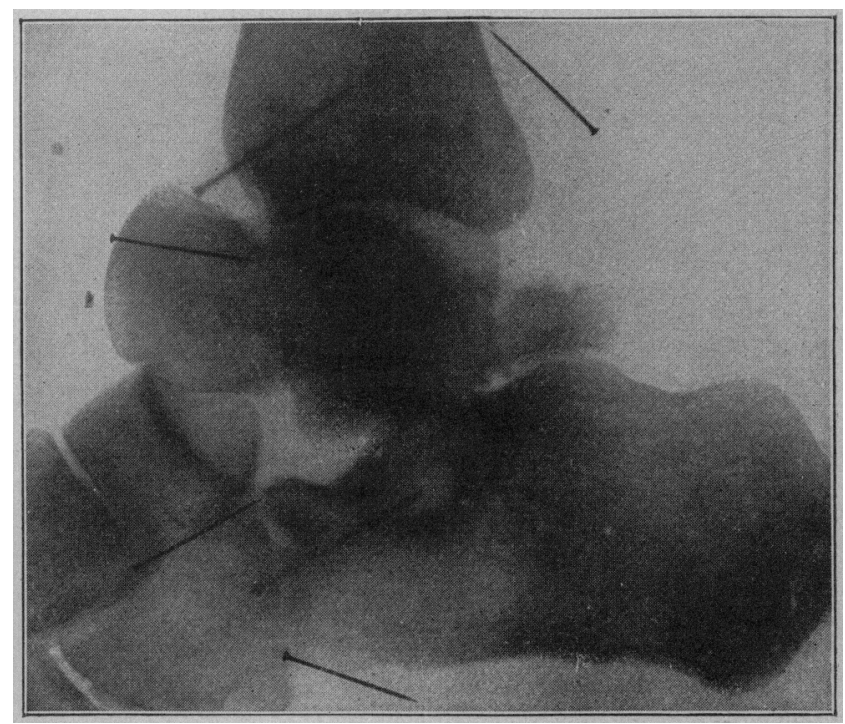

Fig. 1.-Dislocation of the astragaloscaphoid joint and fracture of the posterior part of the astragalus.

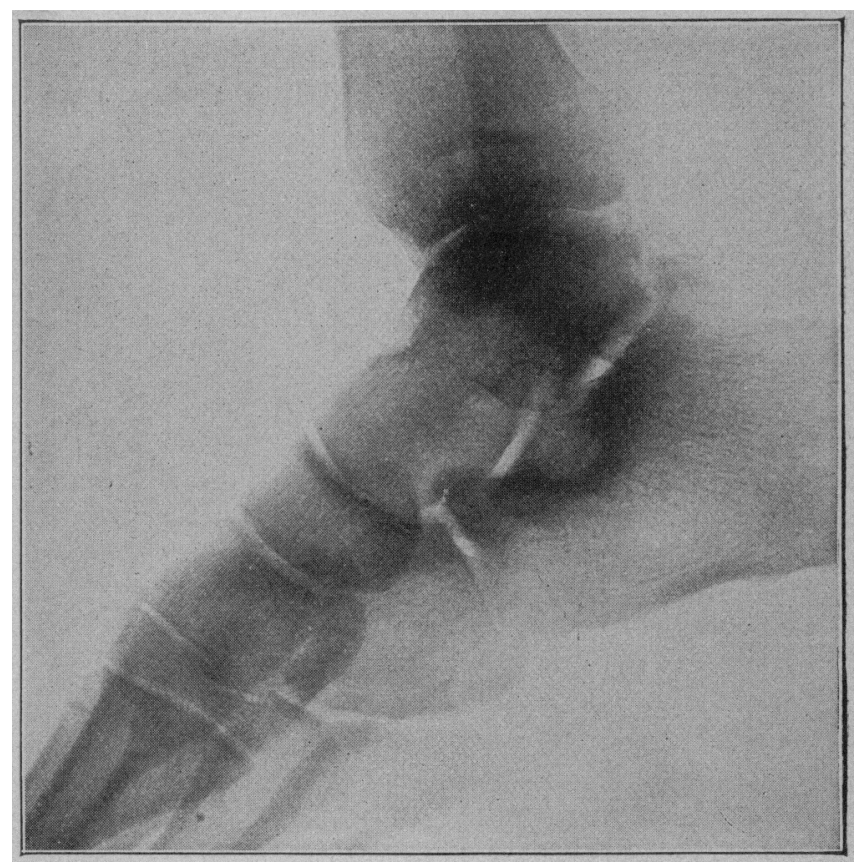

Fi- 2.-Dislocation reduced.

Dislocations of the knee compose less than 2 per cent. of all dislocations. Of these about one-half are of the forward variety, and 20 per cent. of this type are compound. Up to this time there have been reported 270 cases of knee dislocations including all varieties, 113 of these being of the anterior type, this making the one hundred and fourteenth case to be reported. 
Subastragaloid dislocations are even much more rare than dislocations of the knee, there being in the literature 86 cases. Of these 50 have been inward, 21 outward, 8 anterior and 7 posterior, this making the eighth case of posterior subastragaloid dislocation of the foot to be reported.

CASE 1.-History.-The patient, William W., aged 47 , was sent to the hospital July 31 by Dr. $K$. While the patient was unharnessing a horse in a stable in the country, the animal had become frightened and had run out of the door. In his attempt to catch it, the patient stepped in a ditch, sliding down an incline, throwing his body forward, hyperextending his right leg so that his right foot was turned up on his left thigh. The leg was straightened out and a-side splint put on and the patient sent to the hospital. The leg was said to be fractured, and the deformity made the diagnosis appear to be a plausible one without an examination, so the patient was anesthetized.

Examination.-The limb was extended and the lateral axis about normal, but the leg was on a plane anterior to the thigh, and the lower extremity of the femur could be plainly felt in the popliteal space. The quadriceps extensor was lax, the patella was freely movable and seemed to fall back into a large space.

Treatment and Result.-The diagnosis of an anterior dislccation of the knee could readily be made, and the reduction was easily brought about by extension and direct pressure on the femur and tibia, pushing the former forward and the latter downward and backward. A plaster cast from the upper part of the thigh to the foot was applied and allowed to remain on until September 10, a period of six weeks cast was then removed, a tight bandage applied, and gradual use of the leg begun. On October 4 the patient was discharged walking normally. A radiograph taken after the dislocation was reduced showed no fracture and the leg in normal position.

CAse 2.-History.-The patient, W. P. B., aged 33, was a brakeman on the Baltimore and Ohio railroad. This man was admitted to the hospital August 29. He had fallen from the top of a freight-car, striking on his feet. He felt the right foot give way, and was unable on account of pain to stand on it after that time.

Examination.-The foot was much swollen, very tender to the touch. The front part of the foot was shortened and showed in the midtarsal region a marked prominence, which was recognized as the head of the astragalus. An $x$-ray photograph (Fig. 1), showed a dislocation of the astragaloscaphoid joint with the head of the astragalus riding on the upper surface of the scaphoid, and a fracture of the posterior part of the astragalus, probably the external tubercle of the posterior surface to which is attached the posterior fasciculus of the external lateral ligament. Through the neck of the astragalus there was noted an incomplete seam fracture.

Treatment and Result.-Under anesthesia the dislocation was reduced without material difficulfy by making direct pressure on the head of the astragalus, and at the same time drawing the anterior part of the foot strongly forward. The foot and leg were then encased in a snugly fitting plaster cast. A second $x$-ray photograph (Fig. 2) showed the dislocation reduced, and the fracture in satisfactory position. The patient was discharged October 4 with a very satisfactory result.

31 East North Avenue.

The Treatment of Soft Chancre and Its Glandular Complications with Copper Salts.-Almkvist believes that the amidoacetate and lactate of copper have proved themselves more effective in soft chancre and its glandular complications than any other method which can be used in the ambulatory treatment of patients. The copper salts mentioned differ from the copper salts previously tried in this treatment by the fact that they do not precipitate proteins.

\section{EXPERIMENTAL LUNG ANTHRACOSIS}

\author{
PRELIMINARY NOTE
}

\author{
LEWIS SAYRE MACE, M.D. \\ SAN FRANCISCO
}

The intestinal origin of lung anthracosis was suggested in 1862 by Villaret, ${ }^{1}$ but denied in 1885 by Arnold, ${ }^{2}$ who asserted that the small amount of absorption which he had observed following the feeding of charcoal emulsions was not sufficient evidence on which to accept this theory.

In December, 1905, appeared the first of a series of articles by Van Steenburg and Grysez ${ }^{3}$ of Calmette's laboratory, in which they showed that particles of carbon when injected into the stomach or peritoneal cavity of adult animals were promptly absorbed by the lymph ducts of the mesentery and diaphragm, carried through the thorax to the veins returning to the right heart and finally deposited in the lungs. It was noted that with young animals this result was not obtained.

Following the work of Calmette, Van Steenburg, Grysez, Sommerville ${ }^{4}$ and others, Petit ${ }^{5}$ reported the results of his experiments with six children dying of tuberculosis and other diseases. To these he administered charcoal through a. stomach tube and found on autopsy a more or less general anthracosis in the four who suffered from tuberculosis. He concluded that the presence of tuberculous infection rendered the subject especially liable to intestinally borne anthracosis.

On the contrary, Beitzke, ${ }^{6} \mathrm{Cohn}^{7}$ and Schultz $^{8}$ repeated the experiments of Calmette and his associates without confirming their results. They found that foreign matter injected into the stomach or peritoneal cavity was, in fact, taken up by the lymphatics, but that it was deposited almost entirely in the liver and spleen. Occasionally, it is true, they observed a pulmonary deposit, but this they attributed to the presence of a spontaneous anthracosis, which occurs in at least 10 per cent. of adult laboratory animals. To this fact or to accidental inhalation during feeding experiments they attributed the results of the French observers.

These contradictory results mean that this subject, so important in considering the origin of tuberculosis and other infections, is still an open one. I have therefore tried to devise methods which should eliminate the errors of former experimenters.

Work with charcoal or any black substance was soon discontinued, as it was found, as Beitzke and others had asserted, that a number of control animals showed the presence of a spontaneous black or gray deposit.

What was needed was a substance, not black, which should be easily recognizable on account of its contrasting color, non-toxic and not affected by the body fluids.

Ultramarine blue, one of the most stable of the blue, green or violet coloring matters, seemed to fulfill these requirements. It is chemically a very inert substance and is affected only by the strongest reagents. No substance resembling it could possibly be present as a spontaneous deposit, and its color is easily recognized on autopsy, which is not true of the red or yellow pigments.

1. Villaret: Cas rare d'anthracose suivi de quelques, considera. 1. Vhysiologiques et pathologiques, Paris, 186.

2. Arnold : Nebersuchung über Staub-Inhalation und StaubMetastase, Leipsic, 1885 .

3. Van Steenburg and Grysez: Ann d l'Inst. Pasteur, xix, 786.

4. Van Steenburg and Sommerville: Presse méd., xiv. No. 64

5. Petit: Presse méd., xiv, No. 82

6. Beitzke: Source of Anthracosis of the Lungs, Virchow's Arch. f. Path. Anat. clxxxvil, No. 1.

7. Cohn: Bel klin. Wchnschr, xliii, No. 45 .

8. Schultz: München. med. Wchnschr., liji. No. 35. 